1

2

3

4

11

2

\title{
Increased Riboflavin Production from Activated Bleaching Earth by a Mutant Strain of Ashbya gossypii
}

Satoshi Tajima, ${ }^{1}$ Yoko Itoh, ${ }^{2}$ Takashi Sugimoto, ${ }^{3}$ Tatsuya Kato, ${ }^{1}$ and Enoch Y. Park ${ }^{1,3 *}$

${ }^{1}$ Laboratory of Biotechnology, Department of Applied Biological Chemistry, Faculty of Agriculture, Shizuoka University, 836 Ohya, Suruga-ku, Shizuoka 422-8529, Japan

${ }^{2}$ JST Innovation Satellite Shizuoka, Japan Science and Technology Agency, 3-5-1-Johoku, Naka-ku, Hamamatsu 432-8561, Japan

${ }^{3}$ Laboratory of Biotechnology, Integrated Bioscience Section, Graduate School of Science and Technology, Shizuoka University, 836 Ohya, Suruga-ku, Shizuoka 422-8529, Japan

RUNNING TITLE: RIBOFLAVIN PRODUCTION BY A MUTANT STRAIN OF ASHBYA GOSSYPII

* Corresponding author.e-mail: acypark@ipc.shizuoka.ac.jp (E.Y. Park)

Phone \& fax: +81-54-238-4887 
1 Abstract

2

The production of riboflavin from vegetable oil was increased using a mutant

3 strain of Ashbya gossypii (ATCC 10895). This mutant was generated by treating

4 the wild-type strain with $N$-methyl- $N^{\prime}$-nitro- $N$-nitrosoguanidine (MNNG).

5 Riboflavin production was 10 -fold higher in the mutant compared to the wild-type

6 strain. The specific intracellular catalase activity after $3 \mathrm{~d}$ of culture was 6 -fold

7 higher in the mutant than in the wild-type strain. For the mutant, riboflavin

8 production in the presence of $40 \mathrm{mM}$ hydrogen peroxide was $16 \%$ less than that in

9 the absence of hydrogen peroxide, whereas it was $56 \%$ less for the wild-type strain.

10 The isocitrate lyase (ICL) activity of the mutant was $0.26 \mathrm{mU} / \mathrm{mg}$ of protein during

11 the active riboflavin production phase, which was 2.6-fold higher than the

12 wild-type strain. These data indicate that the mutant utilizes the carbon flux from

13 the TCA cycle to the glyoxylate cycle more efficiently than the wild-type strain,

14 resulting in enhanced riboflavin production. This novel mutant has the potential to be of use for industrial-scale riboflavin production from waste-activated bleaching earth (ABE), thereby transforming a useless material into a valuable bioproduct.

17 [Keywords: Ashbya gossypii, riboflavin, waste activated bleaching earth, strain

18 improvement, biorefinery] 


\section{INTRODUCTION}

Activated bleaching earth (ABE) is a commonly used adsorbent for the removal of carotene, chlorophyll, and other components formed during the refinement of crude vegetable oil (e.g. phosphatides and soaps). ABE is generated when montmorillonite clay is treated with mineral acids (generally sulfuric acid) to elute basic components such as aluminum, iron, and magnesium. The ABE crystal lattice is a three-layered structure of silica-alumina-silica, and its activated porous structure has a large surface area and adsorption capacity (1). During crude oil refinement, ABE adsorbs approximately $40 \%$ of vegetable oil by weight (2) and is disposed of as waste material. Annually, Japan discharges more than 80,000 metric tons of waste ABE.

Traditionally, waste $\mathrm{ABE}$ has been transferred from the oil-refining industry to the cement industry for incineration; however, cement manufacturers have difficulty treating waste $\mathrm{ABE}$ because of its high oil content. In the near future, it is likely that incineration or landfill disposal will become impossible due to environmental restrictions, spoilage of released waste oil, lack of suitable new sites, and need to reduce greenhouse gases. We previously attempted to convert the vegetable oil in waste ABE into useful bioproducts, such as riboflavin, using an oil-utilizing microorganism $(3,4)$. Riboflavin, a yellow water-soluble vitamin, is an essential component of basic cellular metabolism since it is a precursor for flavin mononucleotide (FMN) and flavin adenine dinucleotide (FAD) coenzymes (5). Many microorganisms, plants, and fungi can 
1 biosynthesize riboflavin from carbon sources. However, vertebrates, including humans,

2 lack this ability and must obtain this vitamin from their diet (6). Currently, industrial

3 riboflavin production by microbial fermentation generates approximately 6000 tons per

4 year. Several microorganisms produce high levels of riboflavin, including the fungi

5 Eremothecium ashbyii and Ashbya gossypii, yeast Candida flaveri, and bacteria Bacillus

6 subtilis (7).

$7 \quad$ We investigated the capacity of several microorganisms to produce riboflavin from

8 the vegetable oil present in waste $\mathrm{ABE}$ and determined that A. gossypii was the most

9 efficient $(2,8,9)$. However, this wild A. gossypii strain was still unsuitable for

10 economic large-scale production of riboflavin from waste $\mathrm{ABE}$ because of low

11 riboflavin productivity.

12 In this study, we isolated a mutant strain that overproduced riboflavin using the

13 vegetable oil adsorbed in waste $\mathrm{ABE}$ as a sole carbon source for the process. The

14 mutant was characterized in a 3-L jar fermentor using ABE containing crude vegetable

15 oil as an artificial form of waste ABE. Proteomic analysis was performed on the isolated

16 mutant strain, and the results indicated that the levels of several enzymes involved in the

17 riboflavin synthesis pathway were altered in the mutant strain. 
Strain, media, and culture conditions The A. gossypii (ATCC 10895) strain was used in this study. Cells were grown at $\mathrm{pH} 6.0$ and $28^{\circ} \mathrm{C}$ on a solid medium containing

4 (per liter) 10 g yeast extract (Oriental Yeast Co. Ltd., Tokyo, Japan), 10 g glucose

5 (Wako Pure Chem. Ind. Ltd., Osaka, Japan), and 20 g agar (Shimizu Shokuhin Kaisha,

6 Ltd., Shizuoka, Japan) (pH 6.0). After $3 \mathrm{~d}$ of culture, the agar-plates were stored at $4{ }^{\circ} \mathrm{C}$

$7 \quad$ until further analysis. The seed medium described by Szczesniak et al. (10) was

8 modified and consisted of (per liter): $30 \mathrm{~g}$ corn steep liquor (CSL; Sigma Chem. Co., St.

9 Louis, MO, USA), $10 \mathrm{~g}$ yeast extract (Wako), and $15 \mathrm{~g}$ rapeseed oil ( $\mathrm{pH}$ 6.8). The rapeseed oil was provided by Mizusawa Chem. Ind. Ltd. (Niigata, Japan). The production medium consisted of (per liter): $30 \mathrm{~g}$ gelatin (Wako), $60 \mathrm{~g} \mathrm{CSL}, 1.5 \mathrm{~g}$ glycine (Wako), $1.5 \mathrm{~g} \mathrm{KH}_{2} \mathrm{PO}_{4}, 4.4 \mathrm{mg} \mathrm{CoCl} 2,17.9 \mathrm{mg} \mathrm{MnCl}_{2} \cdot 4 \mathrm{H}_{2} \mathrm{O}, 44.2 \mathrm{mg}$ dissolved in 1 liter of distilled water, and the $\mathrm{pH}$ was adjusted to 6.8 .

The YR medium consisted of (per liter) $10 \mathrm{~g}$ yeast extract and $10 \mathrm{~g}$ rapeseed oil $(\mathrm{pH}$ 6.0), which was used to select for rapeseed oil-utilizing A. gossypii. To screen for riboflavin-overproducing mutants, $100 \mathrm{mM}$ itaconate was added to the YR medium (itaYR) as an antimetabolite. Solid YR and itaYR media were prepared by adding $20 \mathrm{~g} / 1$ agar to each.

A seed culture was grown for $40 \mathrm{~h}$ at $28^{\circ} \mathrm{C}$ on a rotary shaker (Bio Shaker; Takasaki Sci. Instr. Co., Saitama, Japan) at $220 \mathrm{rpm}$. For riboflavin production in flask cultures, 2 
$1 \mathrm{ml}$ of seed culture was inoculated into a 500-ml Erlenmeyer flask containing $50 \mathrm{ml}$ of

2 production medium, and these cultures were grown for $6 \mathrm{~d}$ at $28^{\circ} \mathrm{C}$ on a rotary shaker at

$3200 \mathrm{rpm}$. Artificial waste ABE (Mizusawa Chem. Ind. Co., Niigata, Japan) that adsorbs

4 approximately $40 \%(\mathrm{w} / \mathrm{w})$ crude vegetable oil was used as the supplemental carbon

5 source.

6 Riboflavin production by the wild-type and isolated mutants was compared in a 3-L

7 bioreactor (Bioneer-300, Marubishi, Co., Ltd., Tokyo) containing 1.5 L production

8 medium. The inoculum size was $10 \%(\mathrm{v} / \mathrm{v})$, and the culture was grown with agitation at

$9600 \mathrm{rpm}$ and an aeration rate of $1 \mathrm{vvm}$ at a constant temperature of $28^{\circ} \mathrm{C}$.

Spore isolation, mutagenesis, and mutant screening After 1 week of growth on solid seed medium, the mycelia were isolated by adding $0.5 \mathrm{ml}$ of steam-sterilized distilled water. Zymolyase 20T (0.25 ml) from Arthrobacter luteus (Seikagaku Co.,

13 Tokyo, Japan; $15 \mathrm{mg} / \mathrm{ml})$, and the mycelial suspension $(0.5 \mathrm{ml})$ were mixed and incubated for $30 \mathrm{~min}$ at $37^{\circ} \mathrm{C}$ with gentle shaking. The solution was centrifuged at 2700 $g$ for $5 \mathrm{~min}$, and the resulting pellet was resuspended in $1 \mathrm{ml}$ of distilled water containing $0.03 \%$ Triton $\mathrm{X}-100$. This centrifugation process was repeated twice. The hydrophobic spores of $A$. gossypii were resuspended in $500 \mu 1$ Triton X-100, and $100 \mu 1$ of glycerol was added. The spore suspension was stored at $-80^{\circ} \mathrm{C}$ until further analysis. The spore suspension $\left(500 \mu \mathrm{l} ; 1.0 \times 10^{7} \mathrm{spores} / \mathrm{ml}\right)$ from the wild-type strain was treated with $1 \mathrm{mg} / \mathrm{l} N$-methyl- $N^{\prime}$-nitro- $N$-nitrosoguanidine (MNNG) in TM buffer (200 mM 2-amino-2 hydroxymethyl-1,3-propanediol, $170 \mathrm{mM}$ maleic acid, and $0.03 \%$ Triton 
$1 \mathrm{X}-100, \mathrm{pH} 8.0$ ) for $2 \mathrm{~h}$ at $28^{\circ} \mathrm{C}$. The spores were washed twice with $10 \mathrm{ml} \mathrm{TM}$ buffer,

2 and the resulting pellet was resuspended in $5 \mathrm{ml}$ of sterilized saline solution. The

3 MNNG-treated spores were placed on the itaYR medium and incubated at $28^{\circ} \mathrm{C}$ for

4 6-14 d. Yellow-colored colonies growing in the itaYR medium were selected, and each

5 colony was cultured for an additional $7 \mathrm{~d}$ in the itaYR medium. This screening process

6 was repeated three times.

7 Proteome analysis The wild-type and mutant strains were grown in the YR

8 medium for $72 \mathrm{~h}$ at $28^{\circ} \mathrm{C}$. To isolate the soluble proteins, the cells were washed in

9 distilled water and resuspended in $50 \mathrm{mM}$ potassium phosphate buffer ( $\mathrm{pH} 7.5)$. The

10 cells were then sonicated four times for $30 \mathrm{~s}$ using an ultrasonicator (Vibracell; Sonics

$11 \&$ Materials Inc., Newtown, CT, USA). After centrifugation at 20,000 $\mathrm{g}$ for $5 \mathrm{~min}$ at

$12 \quad 4^{\circ} \mathrm{C}$, the supernatant was collected. This supernatant, which contained the soluble

13 protein fraction, was subjected to two-dimensional electrophoresis proteome analysis at

14 Shimadzu Biotech (Tsukuba, Japan).

Analytical method Cell-free extracts to assess enzyme activity were prepared in

16 buffer containing $50 \mathrm{mM}$ imidazole/ $\mathrm{HCl}(\mathrm{pH} 7.5), 10 \mathrm{mM} \mathrm{KCl}, 1 \mathrm{mM}$ EDTA (pH 8.0),

$175 \mathrm{mM} \mathrm{MgSO}_{4}, 5 \mathrm{mM}$ dithiothreitol (DTT), $1 \mathrm{mM}$ phenylmethylsulfonyl fluoride

18 (PMSF), and 30\% glycerin. The harvested cells were washed in buffer and sonicated

19 four times for $30 \mathrm{~s}$ using an ultrasonicator. The suspension was centrifuged for $30 \mathrm{~min}$

20 at $20,000 \mathrm{~g}$ and $4{ }^{\circ} \mathrm{C}$. The supernatant was collected for assessment of enzyme activity 
and protein concentration. The latter was measured by Bradford method using a protein assay kit (Bio-Rad, Hercules, CA, USA).

Isocitrate lyase (ICL) activity was assayed according to a previously reported method (11). The reaction buffer contained $25 \mathrm{mM}$ imidazole/ $\mathrm{HCl}, 4 \mathrm{mM}$ phenylhydrazine/ $\mathrm{HCl}, 5 \mathrm{mM} \mathrm{MgCl} 2,1 \mathrm{mM}$ EDTA, $5 \mathrm{mM}$ dithiothreitol, and $4 \mathrm{mM}$ threo- $D L$-isocitrate. The reaction was initiated by the addition of glyoxylate phenylhydrazone $\left(\varepsilon=14630 \mathrm{M}^{-1} \mathrm{~cm}^{-1}\right)$, and the absorbance was measured at $340 \mathrm{~nm}$ at $30^{\circ} \mathrm{C}$. One unit of enzyme activity was defined as the amount of the enzyme required to produce one micromole of glyoxylate phenylhydrazone per minute. Catalase activity was measured using the catalase assay kit (Cayman Chem. Co., Ann Arbor, MI, USA).

The residual vegetable oil concentration was measured by the solvent extraction method. Prior to sampling, the culture broth was thoroughly mixed, and a 10-ml sample was withdrawn. $n$-Hexane $(10 \mathrm{ml})$ was added to the sampled culture broth, and the two were vigorously shaken for $1 \mathrm{~min}$ in a screw-capped Falcon tube, followed by centrifugation at $2000 \mathrm{~g}$ for $15 \mathrm{~min}$. The upper hexane layer was evaporated by blowing with nitrogen gas on a heat block, and the residue was dried at $75^{\circ} \mathrm{C}$ for $3 \mathrm{~h}$. The weight of the extracted oil was measured.

To measure the riboflavin concentration, $0.5 \mathrm{ml}$ of culture broth was mixed with 4.5 $\mathrm{ml}$ of distilled water and centrifuged at $1000 \mathrm{~g}$ for $10 \mathrm{~min}$. The supernatant $(1.6 \mathrm{ml})$ was removed and thoroughly mixed with $0.8 \mathrm{ml}$ of $1 \mathrm{~N} \mathrm{NaOH}$ and $5 \mathrm{ml}$ of $50 \mathrm{mM}$ phosphate buffer ( $\mathrm{pH} 7.0$ ), and then the samples was centrifuged at $9000 \mathrm{~g}$ for $5 \mathrm{~min}$. The 
supernatant $(0.8 \mathrm{ml})$ was filtered, and the optical density at $444 \mathrm{~nm}$ was measured. The obtained riboflavin concentration was converted using a conversion factor of 127.297 mg (unit of optical density per liter) (12). In the case of the culture broth containing ABE, the sample was thoroughly mixed with $0.8 \mathrm{ml}$ of $1 \mathrm{~N} \mathrm{NaOH}$ and centrifuged at $2000 \mathrm{~g}$ for $15 \mathrm{~min}$. The supernatant was used to measure the riboflavin concentration.

\section{RESULTS AND DISCUSSION}

\section{Isolation and screening of riboflavin-overproducing variants created by} MNNG-induced mutation The survival rates of wild-type A. gossypii cultured in medium containing various concentrations of MNNG relative to that in medium without MNNG was as follows: $15 \%$ in medium containing $30 \mathrm{mg} / \mathrm{l} \mathrm{MNNG} ; 10 \%$ in medium containing $60 \mathrm{mg} / \mathrm{MNNG}$; 5\% in medium containing $90 \mathrm{mg} / \mathrm{l} \mathrm{MNNG}$; and 1\% in medium containing $100 \mathrm{mg} / 1 \mathrm{MNNG}$ (data not shown). Based on these data, $100 \mathrm{mg} / 1$ was selected as the optimal concentration of MNNG for inducing mutation.

The MNNG-induced mutant colonies were grown on agar-itaYR medium containing $100 \mathrm{mM}$ itaconate as the antimetabolite. The total number of colonies that grew in the screening medium was 186,025 . There were 571 intensely yellow-colored colonies (data not shown), and these were selected by visual identification for follow-up analysis. These yellow colonies were cultured in YR medium in a test tube. Among the 571 variants, there were 18 mutants that produced more than $250 \mathrm{mg} / 1$ of riboflavin, and these were selected for follow-up studies. In contrast, the wild-type strain produced only 
$150 \mathrm{mg} / \mathrm{l}$ of riboflavin. The riboflavin production levels of eight mutants that were

2 identified as high-level producers were evaluated in 500-ml flask cultures using the

3 production medium. The Mutant 13a strain produced $3.8 \mathrm{~g} / \mathrm{l}$ of riboflavin, which was

4 3-fold higher than that produced by the wild-type strain (Fig. 1A). On YR agar plates,

5 the mycelia of the wild type spread out to a greater extent than those of mutant $13 \mathrm{a}$;

6 however, the intensity of the yellow color of the mutant 13a strain was much stronger

7 than the wild-type (Fig. 1B). The morphology of mutant 13a in the liquid medium

8 showed that the organism tended to aggregate and form pellets, unlike the wild-type

9 strain that spread its mycelia throughout the medium (data not shown).

Phenotypic changes in the mutant strain To investigate the difference in

11 riboflavin production between the wild-type and mutant 13a strains, the itaconate resistance of the two strains was compared using YR medium containing 0-100 mM itaconate. In the presence of $100 \mathrm{mM}$ itaconate, the dry cell weight of the wild-type strain was one-third of that in the presence of $50 \mathrm{mM}$ itaconate (Fig. 2A), while the dry cell weight of mutant $13 \mathrm{a}$ was not affected by the presence of itaconate. Riboflavin production by mutant $13 \mathrm{a}$ in the presence of $100 \mathrm{mM}$ itaconate was $0.38 \mathrm{~g} / \mathrm{l}$, which was $50 \%$ lower than the amount produced in the absence of itaconate (Fig. 2B). In the wild-type strain, riboflavin production in the presence of $100 \mathrm{mM}$ itaconate was reduced to $70 \%$ of that in the absence of itaconate. The specific riboflavin concentration of the mutant 13a strain was 5-fold higher than that of the wild-type strain at every itaconate concentration range (Fig. 2C). These results indicated that the mutant 13a strain is 
1 resistant to itaconate, and it can maintain high riboflavin productivity even in the

2 presence of high itaconate concentrations.

3 Proteomic analysis was performed to investigate whether there were changes in the

4 expression of proteins involved in the riboflavin metabolic pathway in the mutant strain.

$5 \quad$ During the riboflavin production phase in the mutant 13a strain, there was increased

6 expression of five proteins: thioredoxin peroxidase, cytoplasmic thioredoxin isoenzyme,

7 2-methylbutyraldehyde reductase, NADPH oxidoreductase, and phosphoglycerate

8 kinase. However, the expression of mitochondrial cytochrome b2 decreased in this

9 mutant strain. Oxidoreductases catalyze the transfer of electrons from a fatty acid to

10 another hydrogen or electron acceptor. Thioredoxin peroxidase is a mitochondrial

11 antioxidant protein that regulates basal intracellular levels of hydrogen peroxide, and it

12 protects against reactive oxygen species-induced damage by catalyzing the reduction of

13 hydrogen peroxide into water (13-15). In addition, Kowaltowski et al. (16)

14 demonstrated that thioredoxin peroxidase and catalase function together to maintain cell

15 viability and protect the mitochondria from reactive oxygen species. After $3 \mathrm{~d}$ of culture,

16 the mutant 13a strain exhibited specific intracellular catalase activity that was 6-fold

17 higher than that in the wild-type strain (Fig. 3A). To confirm the resistance of the

18 mutant 13a strain to reactive oxygen species, its resistance to hydrogen peroxide was

19 investigated. When the mutant 13a and wild-type A. gossypii strains were cultured in

20 YR medium containing $40 \mathrm{mM}$ hydrogen peroxide, riboflavin production levels were

21 maintained at $84 \%$ and $44 \%$, respectively, in comparison to the levels in medium 
1 without hydrogen peroxide (Fig. 3B). In comparison to the wild-type strain, the mutant

2 13a strain had developed hydrogen peroxide resistance. Cytochrome $b$, an

3 electron-transfer protein, mediates a wide range of functions during a multitude of

4 different redox processes. The reduced levels of mitochondrial cytochrome $b 2$

$5 \quad$ suggested that catalytic activity decreased during mitochondrial oxidative

6 phosphorylation in the mutant 13 a strain.

$7 \quad$ When vegetable oil is used as the sole carbon source, the glyoxylate cycle assumes

8 an essential role in mediating cell growth and riboflavin production. ICL, the key

9 enzyme in this metabolic pathway, converts isocitrate into glyoxylate, which contributes

10 to cell growth and riboflavin synthesis $(17,18)$. The ICL activity of the two strains was

11 compared (Fig. 4). The specific ICL activity of the wild-type strain was $0.32 \mathrm{mU} / \mathrm{mg}$ of

12 protein on the first day of culture, suggesting that the ICL activity contributed to the

13 increased mycelial growth of the wild-type strain initially. However, the ICL activity of

14 the mutant 13a strain gradually increased to $0.26 \mathrm{mU} \mathrm{mg} /$ protein on the third day of

15 culture, which was 2.6-fold higher than that of the wild-type strain at this time point

16 during the active riboflavin production phase. These data indicate that the mutant strain

17 utilizes carbon flux from the TCA cycle to the glyoxylate cycle strain more efficiently

18 than the wild-type strain.

Riboflavin production using the mutant 13a strain Riboflavin production by

20 the two strains was compared in a 3-L jar fermentor. The oxygen consumption of the

21 mutant 13a strain was lower than that of the wild-type strain because of the decreased 
1 expression of cytochrome $b 2$. The decrease in mitochondrial cytochrome $b 2$ might

2 lower the catalytic activity during mitochondrial oxidative phosphorylation, resulting in

3 decreased oxygen consumption and less mycelial growth (Fig. 5A). Higher ICL activity

4 of mutant than that of wild-type strain (Fig. 4) accelerates carbon flux from TCA cycle

5 to glyoxylate cycle, which may be another reason of decreased mitochondrial oxidative

6 phosphorylation, resulting in decreased oxygen consumption. When nonfermentable

7 carbon source was used in the culture of succinate dehydrogenase-deleted

8 Kluyveromyces lactis, oxygen consumption was one-eighth that of wild-type strain (19),

9 because of using alternative pathway, glyoxylate cycle.

10 The maximum riboflavin concentrations of the mutant 13a and wild-type strains

11 were 3.7 and $0.8 \mathrm{~g} / \mathrm{l}$, respectively (Fig. 5B). In the case of the wild-type strain, the residual oil concentration after $6 \mathrm{~d}$ of culture was $0.8 \mathrm{~g} / \mathrm{l}$ in contrast to $2.8 \mathrm{~g} / \mathrm{l}$ for the

13 mutant 13a strain (Fig. 5B). Therefore, the oil consumption of the mutant 13a strain was

14 lower than the wild-type strain. However, the riboflavin yield based on the consumed

15 substrate was $0.08 \mathrm{~g}$ riboflavin/g consumed oil, which was 4-fold higher for the mutant

16 as compared to the wild-type strain.

17 When $75 \mathrm{~g} / 1$ of artificial ABE waste containing $50 \mathrm{~g} / 1$ of crude rapeseed oil was 18 used, the riboflavin concentration increased by 1.6 fold to $6.0 \mathrm{~g} / \mathrm{l}$ (Fig. 6). The effect of $19 \mathrm{ABE}$ on riboflavin levels produced by A. gossypii cultures using vegetable oil as the 20 carbon source has been previously reported (8). After $48 \mathrm{~h}$ of culture, when a nitrogen 21 mixture containing $7.5 \mathrm{~g}$ of yeast extract and $3.75 \mathrm{~g}$ of glycine was added to the culture 
1 with the same concentration of carbon source, the riboflavin concentration significantly

2 increased and reached $5.5 \mathrm{~g} / 1$ on the third day of culture. The increased riboflavin

3 production rate (Fig. 6) was maintained, and the maximum riboflavin concentration

4 reached $8.7 \mathrm{~g} / 1$ after $6 \mathrm{~d}$ of culture. The riboflavin production yield based on the

5 consumed substrate was $0.17 \mathrm{~g}$ riboflavin/g of substrate, which was 8-fold higher than

6 the wild type.

$7 \quad$ At the end of the culture, ABE was separated from the culture broth, and the

8 precipitate $\left(\mathrm{ABE}\right.$ cake) was dried at $105^{\circ} \mathrm{C}$ for $2 \mathrm{~h}$. More than $80 \%(\mathrm{w} / \mathrm{w})$ of the

9 produced riboflavin was adsorbed into ABE, causing formation of a thick yellow

10 powder. The amount adsorbed onto $\mathrm{ABE}$ was $20 \mathrm{mg}$ of riboflavin/g $\mathrm{ABE}$ (data not

11 shown).

12 The results of this study demonstrated that in comparison to the wild-type strain, the

13 MNNG-induced mutant 13a strain, which used ABE as the oil absorbent, improved

14 riboflavin production by 10 -fold. The mutant 13 a strain exhibited higher specific

15 intracellular catalase activity after $3 \mathrm{~d}$ of culture, and this level was 6-fold higher than

16 the wild-type strain. In the presence of $40 \mathrm{mM}$ hydrogen peroxide, the mutant 13a strain

17 maintained $84 \%$ of the original level of riboflavin production in the absence of

18 hydrogen peroxide, whereas the wild-type strain only retained $44 \%$. These data

19 suggested that the mutant 13a strain was resistant to hydrogen peroxide. The ICL

20 activity of the mutant 13 a strain was $0.26 \mathrm{mU} / \mathrm{mg}$ of protein during the active riboflavin

21 production phase, which was 2.6-fold higher than the wild-type strain. This indicates 
1 that the mutant $13 \mathrm{a}$ strain utilizes the carbon flux from the TCA cycle to the glyoxylate

2 cycle more efficiently than the wild-type strain, resulting in enhanced riboflavin

3 production.

4 In summary, this study identified a novel mutant of A. gossypii that has the

5 potential to be used in industrial-scale riboflavin production from waste ABE, and

6 showed that a useless material like waste ABE can be transformed into a value-added

7 bioproduct.

8

\section{ACKNOWLEDGMENT}

This study was a part of a comprehensive support program for the creation of regional innovation in the Japan Science and Technology Agency.

\section{REFERENCES}

1. Rautureau, M. and Mifsud, A.: Etude par microscope electronique des different etats d'hydration de la sepiolite. Clay Menerals, 12, 309-318 (1977).

2. Park, E.Y., Kato, A., and Ming, H.: Utilization of waste activated bleaching earth containing palm oil in riboflavin production by Ashbya gossypii. J. Am. Oil Chem. Soc., 81, 57-62 (2004). 
1 3. Lim, S.H., Choi, J.S., and Park, E.Y.: Microbial production of riboflavin using

2 riboflavin overproducers, Ashbya gossypii, Bacillus subtilis, and Candida famate: an overview. Biotechnol. Bioprocess. Eng., 6, 75-88 (2001).

4. Lim, .S.H., Ming, H., Lim, S.H., and Choi, J.S.: Improvement of riboflavin production using mineral support in the culture of Ashbya gossypii. Food Technol. Biotechnol., 41, 137-144 (2003).

5. Fraaije, M.W. and Mattevi, A.: Flavoenzymes: diverse catalysts with recurrent features. Trends Biochem. Sci., 25, 126-132 (2000).

6. Bowman, B.B., Mccormick, D.B., and Rosenberg, I.H.: Epithelial transport of water-soluble vitamins. Annu. Rev. Nutr., 9, 187-199 (1989).

7. Stahmann, K.P., Revuelta, J.L., and Seulberger, H.: Three biotechnical process using Ashbya gossypii, Candida famata, or Bacillus subtilis compete with chemical riboflavin production. Appl. Microbiol. Biotchnol., 53, 509-516 (2000).

8. Ming, H., Pizarro, A.V.L., and Park, E.Y.: Application of waste activated bleaching earth containing rapeseed oil on riboflavin production in the culture of Ashbya gossypii. Biotechnol. Prog., 19, 410-417 (2003).

9. Park, E.Y. and Ming, H.: Oxidation of rapeseed oil in waste activated bleaching earth and its effect on riboflavin production in culture of Ashbya gossypii. J. Biosci. Bioeng., 97, 59-64 (2004). 
10. Szczesniak, T., Karabin, L., Szczepanowska, M., and Wituch, K.: Biosynthesis of riboflavin by Ashbya gossypii. I. The influence of fats of the animal origin on the riboflavin production. Acta. Microbiol. Pol. Ser. B, 3, 29-34 (1971).

11. Dixon, G.H. and Kornberg, H.L.: Assay methods for key enzymes of the glyoxylate cycle. Biochem. J., 72, 3P (1959).

12. Sauer, U., Hatzimanikatis, V., Hohmann, H.-P., Manneberg, M., and van Loon, A.P.G.M., Bailey, J.E.: Physiology and metabolic fluxes of wild-type and riboflavin- producing Bacillus subtilis. Appl. Environ. Microbiol., 62, 3687-3696 (1996).

13. Zhang, P., Liu, B., Kang, S.W., Seo, M.S., Rhee, S.G., and Obeid, L.M.: Thioredoxin peroxidase is a novel inhibitor of apoptosis with a mechanism distinct from that of Bcl-2. J. Biol. Chem., 272, 30615-30618 (1997).

14. Demasi, A.P.D., Pereira, A.G., and Netto, L.E.S.: Cytosolic thioredoxin peroxidase I is essential for the antioxidant defense of yeast with dysfunctional mitochondria. FEBS Lett., 509, 430-434 (2001).

15. Chae, H.Z., Kim, H.J., Kang, S.W., and Rhee, S.G.: Characterization of three isoforms of mammalian peroxiredoxin that reduce peroxides in the presence of thioredoxin. Diabetes Res. Clin. Pract., 45, 101-112 (1999). 
16. Kowaltowski, A., Vercesi, A.E., Rhee, S.G., and Netto, L.E.S.: Catalase and thioredoxin peroxidase protect Saccharomyces cerevisiae against $\mathrm{Ca}^{2+}$-induced mitochondrial membrane permeabilization and cell death. FEBS Lett., 473, 177-182 (2000).

17. Schmidt, G., Stahmann, K.P., Kaesler, B., and Sahm, H.: Correlation of isocitrate lyase activity and riboflavin formation in the riboflavin overproducer Ashbya gossypii. Microbiol., 142, 419-426 (1996).

18. Kanasama, S., Tajima, S., and Park, E.Y.: Isocitrate dehydrogenase and isocitrate lyase are essential enzymes for riboflavin production in Ashbya gossypii. Biotechnol. Bioproc. Eng., 12, 92-99 (2007).

19. Saliola, M., Bartoccioni, P.C., De Maria, I., Lodi, T., Falcone, C.: The deletion of the succinate dehydrogenase gene KISDH1 in Kluyveromyces lactis does not lead to respiratory deficiency. Eukaryot. Cell, 3, 589-597 (2004). 


\section{Figure legends}

FIG. 1. Riboflavin concentration (A) and colony formation in YR medium (B). Mutants were cultured for $6 \mathrm{~d}$ in 500-ml flasks containing $50 \mathrm{ml}$ production medium.

$5 \quad$ W.T. and 13a denote the wild type and isolated mutant strains, respectively.

FIG. 2. Effect of itaconic acid concentration on mycelial growth (A), riboflavin

7 concentration (B), and specific riboflavin concentration (C) in the mutant 13a and

8 wild-type strains. Both the mutant 13a and wild-type strains were cultured in 500-ml

9 flasks containing $50 \mathrm{ml} \mathrm{YR} \mathrm{medium} \mathrm{and} \mathrm{0-100} \mathrm{mM} \mathrm{itaconic} \mathrm{acid} \mathrm{for} 4 \mathrm{~d}$.

FIG. 3. Specific catalase activity of mutant 13a and wild-type strains during culture

11 in 500-ml flasks containing $50 \mathrm{ml} \mathrm{YR} \mathrm{medium} \mathrm{(A).} \mathrm{Effect} \mathrm{of} \mathrm{hydrogen} \mathrm{peroxide} \mathrm{on}$ riboflavin production (B). The wild type (white bars) and mutant 13a (black bars) strains were cultured for $6 \mathrm{~d}$ in 500-ml flasks containing $50 \mathrm{ml}$ YR medium with various hydrogen peroxide concentrations.

FIG. 4. Comparison of specific ICL activities of the wild type (white bars) and mutant 13a (black bars) strains. Both strains were cultured for $4 \mathrm{~d}$ in 500-ml flasks containing $50 \mathrm{ml} \mathrm{YR} \mathrm{medium.}$

FIG. 5. Comparison of the dissolved oxygen concentration (A) and concentrations of riboflavin and residual oil (B) in the $3-\mathrm{L}$ jar fermentor of working volume $1.5 \mathrm{~L}$. 
1 Wild-type (dotted lines in A and open squares in B) and mutant 13a (straight lines in A

2 and closed circles in B) strains were cultured in the production medium.

$3 \quad$ FIG. 6. Riboflavin production by the mutant 13a strain under various culture

4 conditions. The strain was cultured in a 3-L jar fermentor of working volume $1.5 \mathrm{~L}$

5 (production medium). The carbon source in the production medium was $50 \mathrm{~g} / 1$ rapeseed

6 oil (opened squares), $75 \mathrm{~g} / \mathrm{l} \mathrm{ABE}$ containing $50 \mathrm{~g} / 1$ rapeseed oil (closed triangles), and

$7 \quad 75 \mathrm{~g} / \mathrm{l} \mathrm{ABE}$ containing $50 \mathrm{~g} / \mathrm{l}$ rapeseed oil with the addition of $5 \mathrm{~g} / \mathrm{l}$ yeast extract and 2.5

$8 \mathrm{~g} / \mathrm{l}$ of glycine after $48 \mathrm{~h}$ of culture (closed squares). 
A

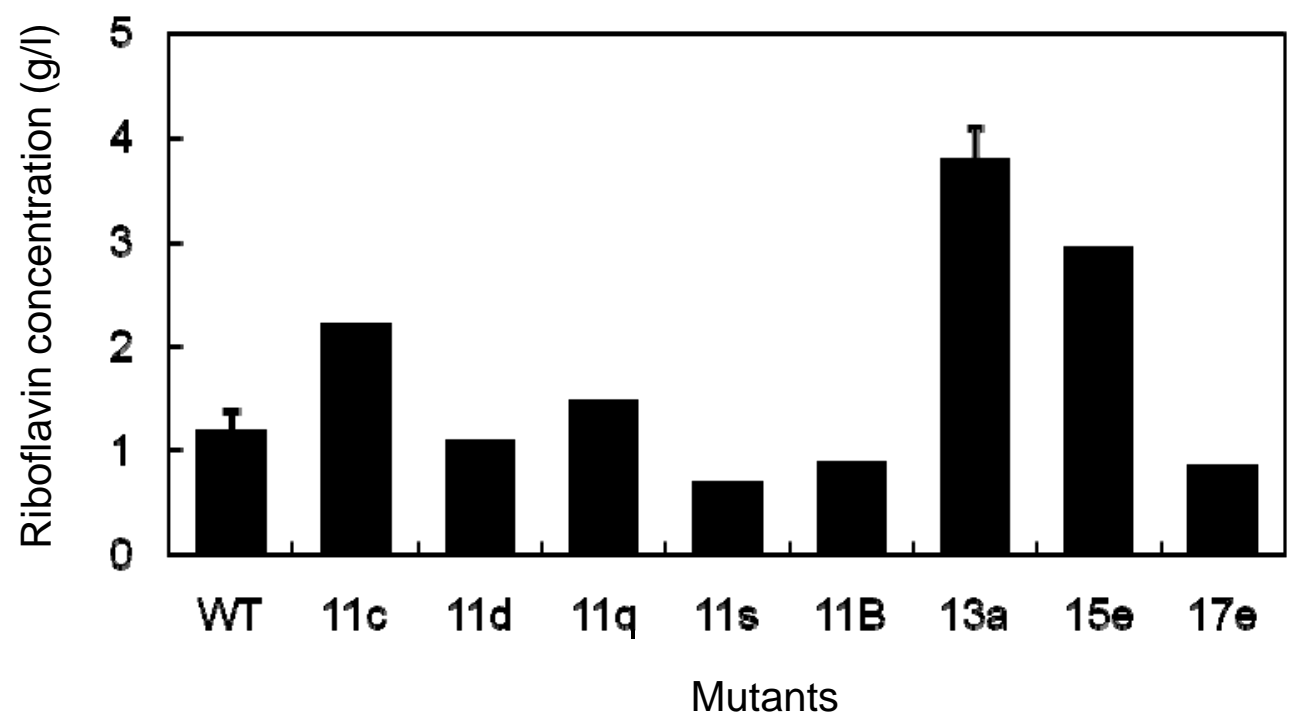

B

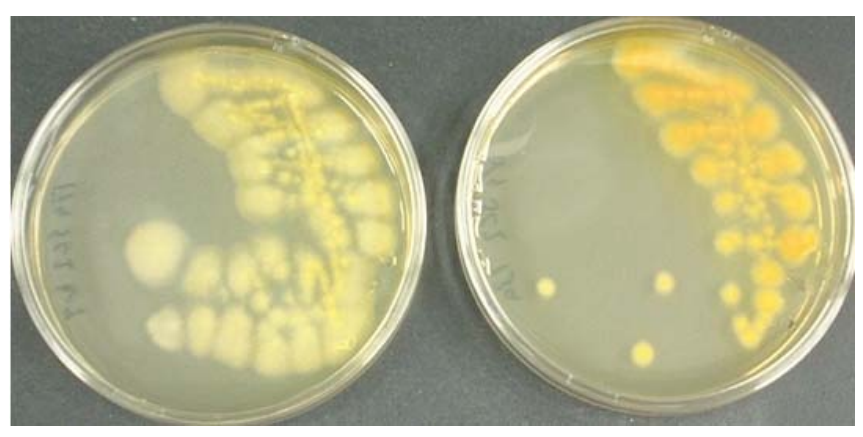

W.T.

$13 a$ 
Tajima et al., Fig. 2
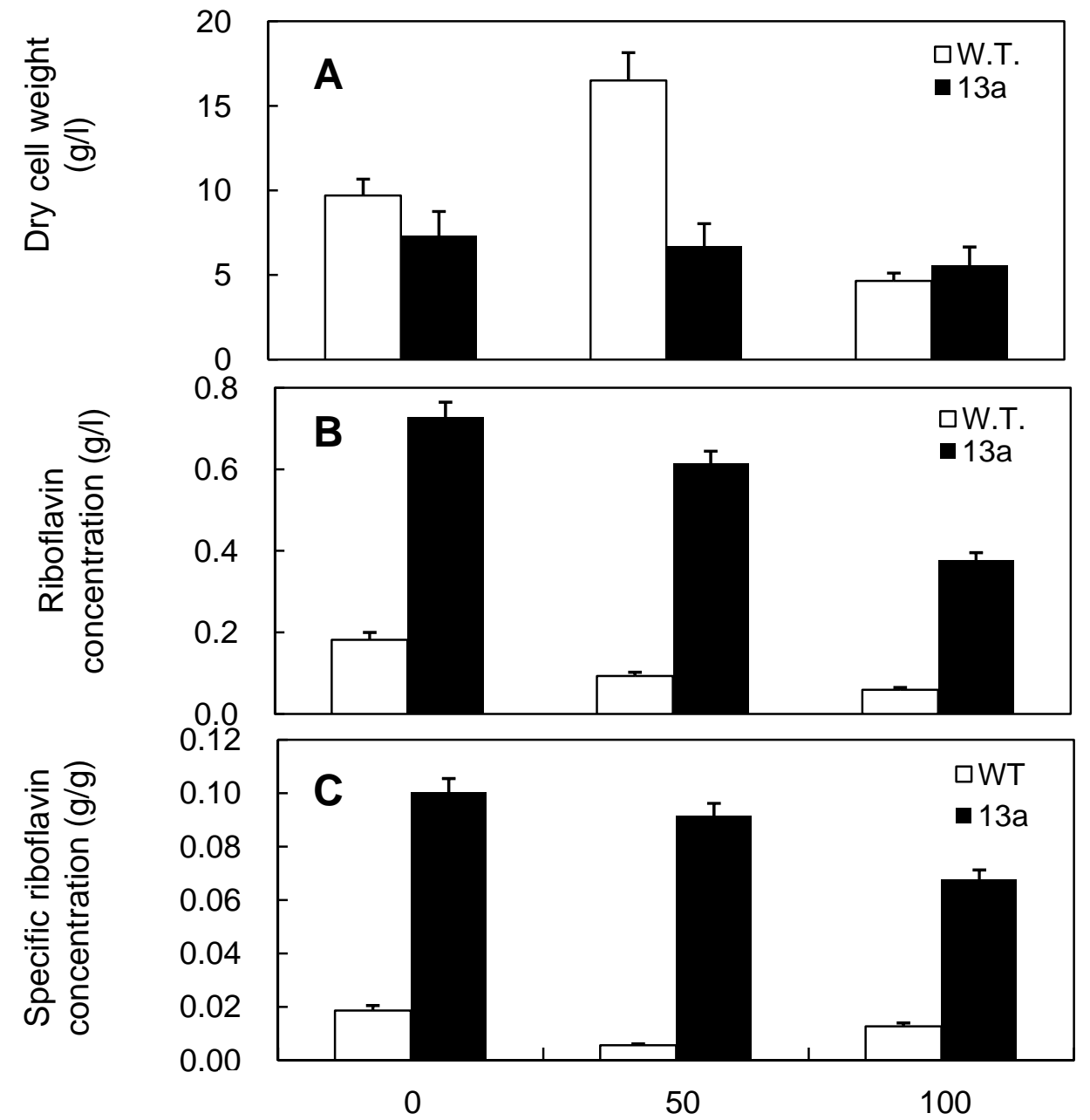

Itaconic acid concentration (mM) 
A

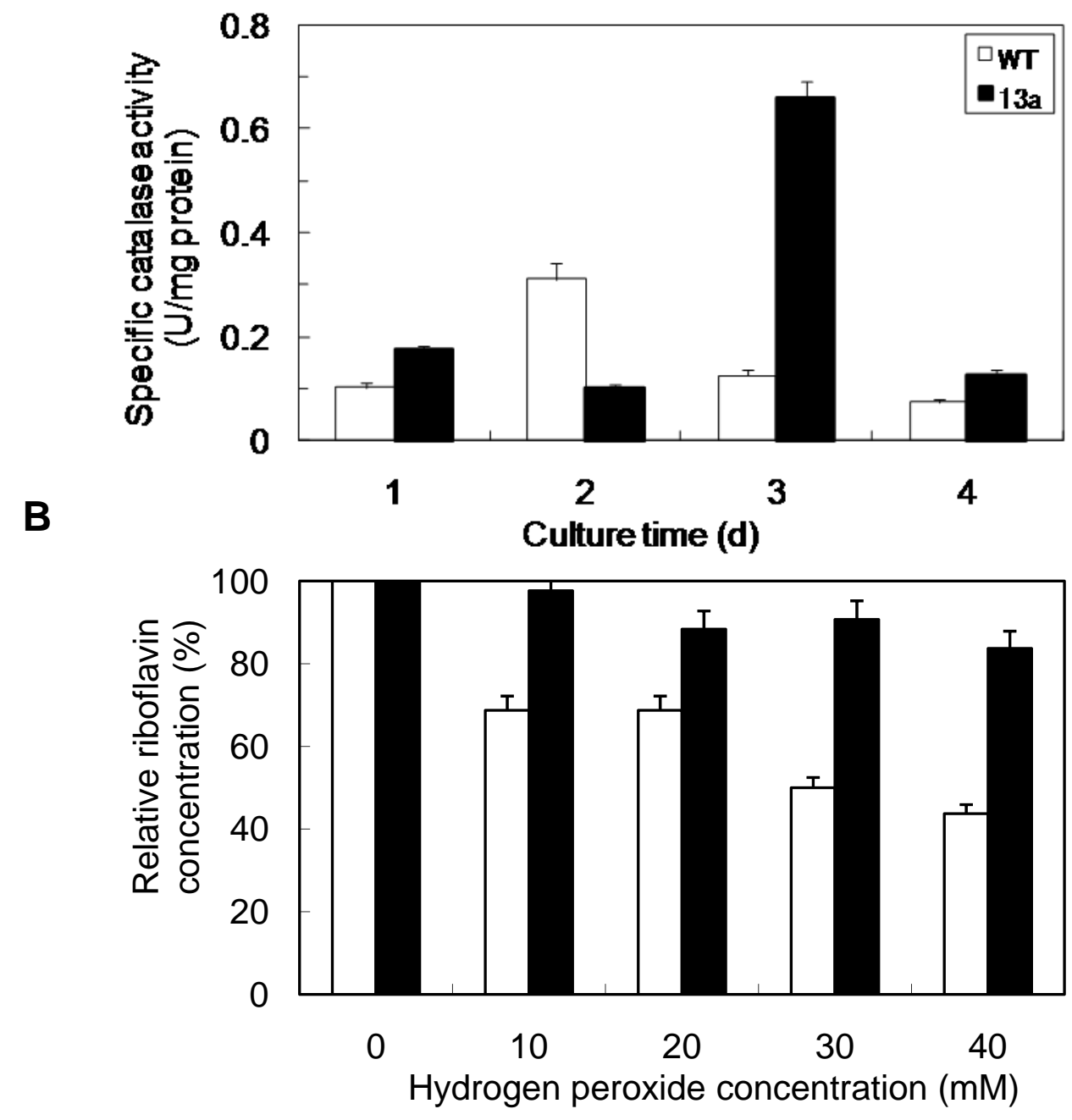


Tajima et al., Fig. 4

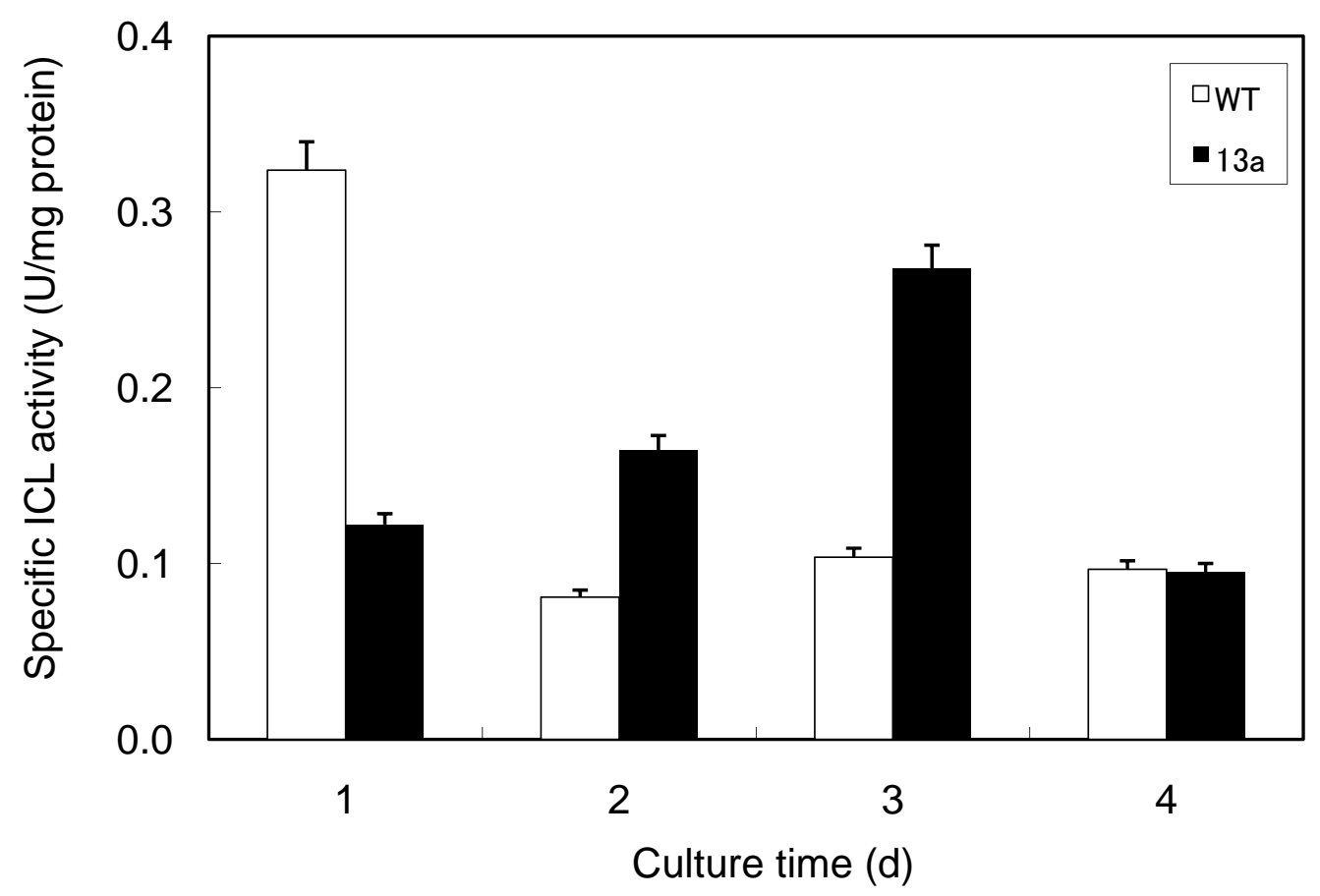




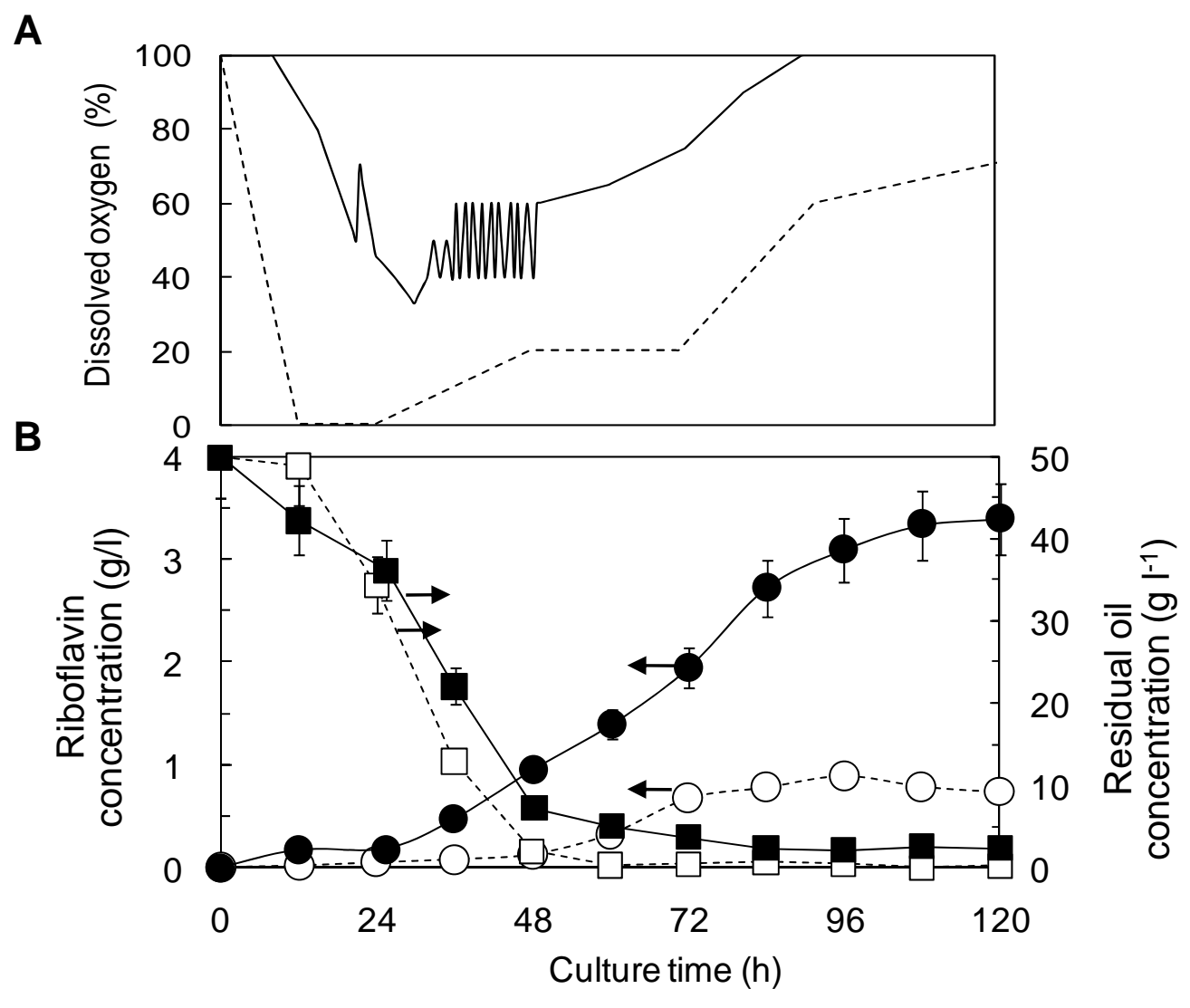




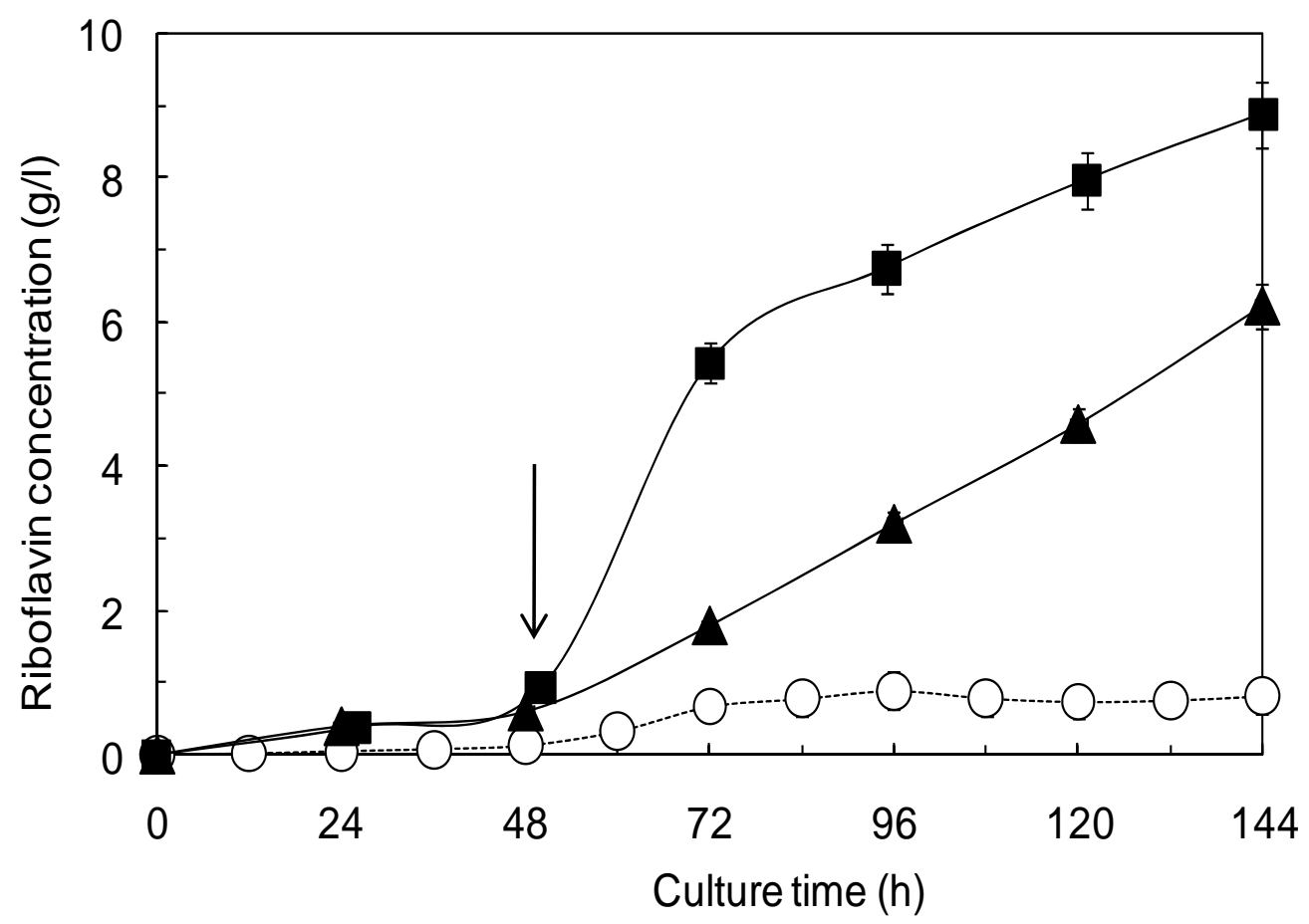

